\title{
Energy Consumption in the Transport Sector: Trends and Forecast Estimates in Morocco
}

\author{
Hasnaa Oubnaki ${ }^{1 *}$, Charifa Haouraji ${ }^{1}$, Badia Mounir ${ }^{2}$, Ilham Mounir ${ }^{2}$ and Abdelmajid Farchi $^{1}$. \\ ${ }^{1}$ Engineering, Industrial Management and Innovation Laboratory, Hassan 1er University - Settat, Morocco \\ ${ }^{2}$ Higher School of Technology, Cadi Ayyad University. Morocco
}

\begin{abstract}
The increase in energy consumption in the transport sector in Morocco makes it necessary to develop reliable energy demand forecasting models. Thus, in this study, five mathematical models were selected to estimate the energy demand of this sector using regression methods for the next ten years. In the development of the models, the gross domestic product, population, vehicle fleet on the road, vehicle registration, activity rate by gender and category, and the rate of working women were taken as parameters. Historical data from 1990 to 2014 were used for the training and testing phases of the models. Using the Partial Least Squares Regression method, the energy consumption in the transport sector is about 8095.49 Ktoe in 2030, and therefore Morocco must continue to strive to reduce energy consumption in order to reduce $\mathrm{CO} 2$ emissions by respecting with its national and international commitments.
\end{abstract}

\section{Introduction}

\subsection{Energy, transport and environment}

According to the forecasts of the International Energy Agency (IEA) [1], the consumption of energy could have a very strong increase of $4.6 \%$ in 2021 compared to 2020. This very strong increase is because of the global containment of Coronavirus, stresses the agency. To continue reducing global energy consumption, countries must meet national and international commitments to reduce greenhouse gas emissions. The creation of reliable energy consumption forecasting models for these sectors is one of the solutions proposed to ensure this reduction.

The transport sector is the most energy-intensive sector that supports all economic and social activities [2]. In order to reduce its impact on energy consumption, all countries have imposed strategies to be followed to achieve this goal. For instance, the production of new cars which tends to replace traditional cars with electric or hybrid vehicles to reduce $\mathrm{CO} 2$ greenhouse emissions. The technical characteristics of these vehicles will help to meet environmental commitments [3].

Like all countries, Morocco is committed to reducing its energy consumption and its greenhouse gas emissions by 2030 through the energy strategy developed since 2009. A part of this reduction will have to be achieved in the transport sector. According to the Moroccan Agency for Energy Efficiency (AMEE), the transport sector is the first energy consumer in Morocco (figure $1)$.

In Fig.1, the distribution of national energy consumption which shows that transport is the most energy intensive sector with a percentage of $39 \%$ of the total consumption in Morocco, then, there is the residential sector with a percentage of $25 \%$, industry by
$21 \%$ and finally the tertiary sector and agriculture with a percentage of $8 \%$ and $7 \%$ respectively [4].

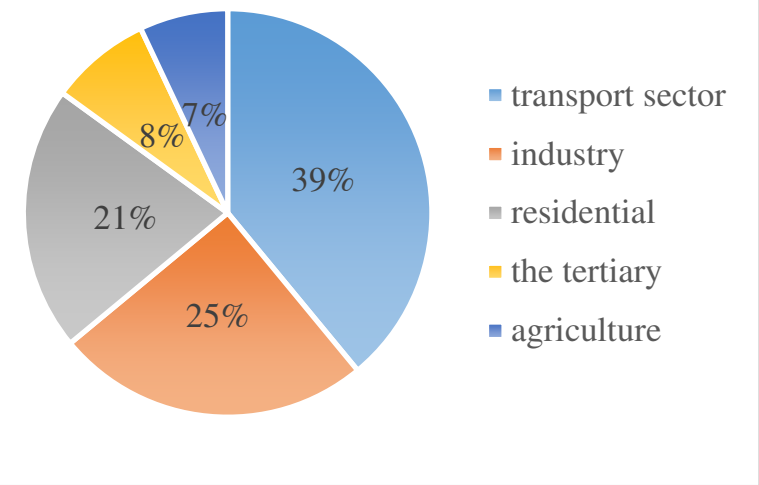

Fig. 1. Breakdown of national energy consumption (source AMEE)

Energy consumption for transport in Morocco is based on fossil fuels for almost $90 \%$ of the total. According to the IEA, it is divided into two energy sources: electric power, which has a very low allocation, and fossil fuels. (Figure 2)

Consequently, Morocco must impose several programs and measures to reduce fuel consumption and $\mathrm{CO} 2$ greenhouse emissions. From where the need to use energy consumption forecasting models [5]. In this study, we will forecast the transport energy consumption in Morocco using the regression methods.

\footnotetext{
*Corresponding author: h.oubnaki@uca.ac.ma
} 


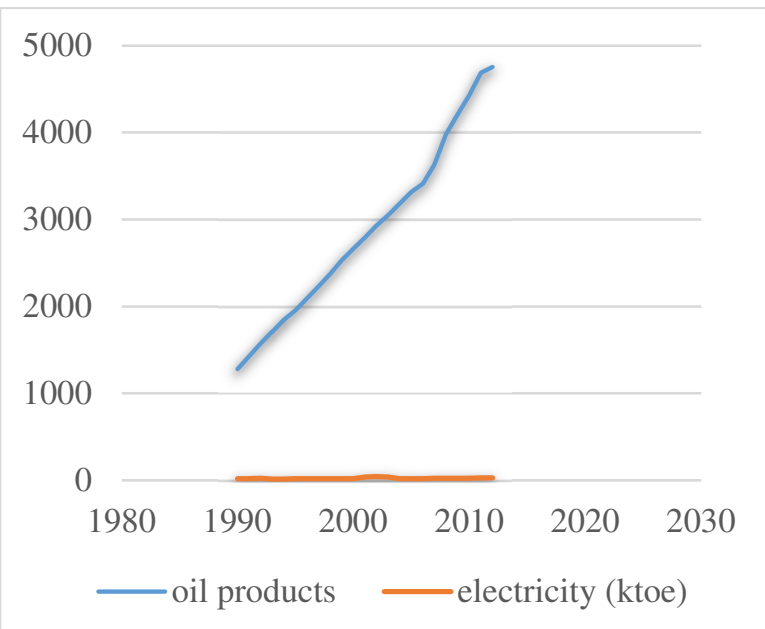

Fig. 2 Energy consumption in the transport sector in Morocco (Kteo)

\subsection{Review of related literature}

As our knowledge, this article is among the first studies of energy consumption forecasts made in Morocco in the transport sector. On the other hand, several modeling and prediction studies of total and sectoral energy have been presented elsewhere by some researchers. For example, Geem [6] developed models for forecasting transport energy in South Korea by considering various independent variables such as gross domestic product (GDP), population (POP), oil price, number of vehicle registrations and amount of passenger transportation. In his study, the artificial neural network (ANN) technique models obtained robust results in terms of RMSE as well as R2, compared to multiple linear regression. In china, Zhang et al. [7] developed a partial least squares regression model with GDP, urbanization rate, passenger transportation amount and freight transportation volume (ton-kilometer) for transport energy forecasting. Maduekwe et al. [8] used the Long rang Alternative Energy Planning (LEAP) model to project future energy demand and greenhouse gas emissions and especially to determine the most efficient A-S-I option in Lagos. The aim of their study is to calculate mileage and energy consumption and $\mathrm{CO} 2$ emissions. Plakandaras et al. [9] predicted air, road and train transport demand for the U.S. domestic market based on econometric and machine learning methodologies.

The forecasting studies have also been the objective of several papers but in relation to other sectors. For example, in the USA Kialashaki et al. [10] developed an energy model capable of predicting energy demand in the residential sector using the artificial neural network (ANN) technique. In 2020, Guefano et al. [11] have demonstrated a model for predicting electricity consumption in Cameroon through a hybrid model. The results show that electricity consumption will reach $2641.632 \mathrm{Gwh}$ in 2025. Gholami et al.[12] developed the energy demand of 1156 buildings in the city of Bologna, their study proposes an archetype coding. In 2019, Beycaet al.[13] employed three alternative popular machine learning tools for rigorous projection of natural gas consumption in the province of Istanbul.
Similarly, in order to maintain sustainable development in Morocco, comprehensive and accurate national energy planning must be undertaken. This reinforces the need to forecast energy consumption to ensure that Morocco is on track with its "energy efficiency" strategy by 2030 .

\subsection{Tools for forecasting energy consumption}

There are several forecasting models that can be used in various sectors, such as residential, industry and transport. Indeed, the energy consumption forecasting models that exist in previous research are multiple and reliable, but with different accuracies. We can generally divide them into three categories [14] :

\section{- Engineering methods}

These methods require physical and thermodynamic laws using complex building and environmental parameters. e.g. Energy Plus, TRNSYS and ESP-r plus.

- Statistical methods

The objective of parametric methods is to construct mathematical models that represent the relationships between load energy demand and the variables that contribute to the allocation of that demand. The main idea of these methods is to determine the relevant variables, and estimate the model coefficients using historical data according to parametric methods. For example, autoregressive models that look for the correlation of energy consumption with selected variables such as POP, GDP, urbanization (which is the method used in this paper).

- Artificial intelligence methods

These are methods that use historical energy consumption data to learn consumption patterns. For example, artificial neural network, etc.

Methods based on artificial intelligence (AI) are also considered learning methods or knowledge-based methods[15].

\section{Research Methodology}

\subsection{Data presentation}

The objective of this study is to develop a model of predicting transport energy demand in Morocco using the regression methods. In the literature, several studies have shown that population growth and the increase in vehicle ownership are the main causes of $\mathrm{CO} 2$ emissions in the road transport sector [16].

In this study, various independent variables are collected to choose the most precise estimate, they are presented in appendix A (Table A-1).

These variables are:

- Population (POP),

- Gross domestic product (GDP),

- Urbanization (URB),

- Price of diesel (PRICED),

- Gas price, (PRICEG)

- Vehicle fleet (FLEET),

- Evolution of the number of vehicles (EVOL),

- Vehicle registration in Morocco (REGIST),

- Credit rate in the transport sector (CREDITR), 
- Rate of active women in Morocco (ACTIVER)

The data of the vehicle fleet, the evolution of the number of vehicles, and the registration of vehicles in Morocco are collected from the MANAR-stat platform, which is a national database of most social, economic, and financial data (such). The data of POP, GDP, URB, the price of diesel, the price of gas, and the credit rate in the transport sector are obtained from the High Commission for the Plan HCP [17] in Morocco, which is the organization in charge of the production, analysis and publication of official statistics in Morocco. The transport Energy consumption (TEC) data comes from the IEA [18]. In this article the historical data are from the year 1990 until 2014.

\subsection{Models construction}

This paper use the regression methods that has been used by many researchers in recent studies [19]. To do this, the data collected is divided into three categories:

- 25 data points (1990-2011) are used to train the regression models and then choose the right models.

- 3 data points (2012-2014) are used to validate the best and most accurate model.

- And 9 data points are then predicted (from 2021 to 2030) to generate the future results.
The next step after the data collection is the models test with the collected variables using the linear regression on the best subsets (see Table 1). Indeed, several models were developed and three models were selected as good models for energy forecasting according to the values of $R^{2}, R_{\text {predicted }}^{2}, R_{\text {adjusted }}^{2}$, Mallows's Cp. The selected models are presented in Table 2. The regression equations for each model are:

(Model 1): POP, GDP, vehicle fleet, price of diesel, rate of credit.

TEC $=-2760+0,0908$ POP + 1,430 GDP + 1,136 FLEET + 57,7 PRICED - 0,01671 CREDITR (1)

(Model 2): POP, GDP, vehicle fleet, evolution of vehicle number, price of diesel and credit rate. TEC $=-2212+0,0687$ POP+ 1,241 GDP
$+1,849$ FLEET- 0,000613 EVOL $+57,8$ PRICED
$-0,01527$ CREDITR.

(Model 3): POP, GDP, vehicle fleet, evolution of vehicle number, price of diesel, credit rate and rate of woman.

TEC $=-2155+0,1208$ POP $+2,019$ GDP

+ 1,959 FLEET- 0,001029 EVOL + 57,4 PRICED

- 0,01495 CREDITR - 57,1 ACTIVER. (3).

Table 1. Results of the regression models

\begin{tabular}{|c|c|c|c|c|c|c|c|c|c|c|c|c|c|c|c|}
\hline vars & $\mathrm{R}$ square & $\begin{array}{l}\mathrm{R} \text { square } \\
\text { adjusted }\end{array}$ & $\begin{array}{l}\mathrm{R} \text { square } \\
\text { predicted }\end{array}$ & $\begin{array}{l}\text { Mallows } \\
\text { Cp }\end{array}$ & S & $\begin{array}{l}\mathrm{P} \\
\mathrm{O} \\
\mathrm{p}\end{array}$ & $\begin{array}{l}\text { G } \\
\mathrm{D} \\
\mathrm{P}\end{array}$ & $\begin{array}{l}\mathrm{P} \\
\mathrm{R} \\
\mathrm{I} \\
\mathrm{C} \\
\mathrm{E} \\
\mathrm{G}\end{array}$ & $\begin{array}{l}\mathrm{R} \\
\mathrm{E} \\
\mathrm{G} \\
\mathrm{I} \\
\mathrm{S} \\
\mathrm{T}\end{array}$ & $\begin{array}{l}\mathrm{F} \\
\mathrm{L} \\
\mathrm{E} \\
\mathrm{E} \\
\mathrm{T}\end{array}$ & $\begin{array}{c}\mathrm{R} \\
\mathrm{O} \\
\mathrm{A} \\
\mathrm{D} \\
\mathrm{N} \\
\mathrm{E} \\
\mathrm{T} \\
\mathrm{W} \\
\mathrm{O} \\
\mathrm{R} \\
\mathrm{K}\end{array}$ & $\begin{array}{l}\text { E } \\
\text { V } \\
\mathrm{O} \\
\mathrm{L}\end{array}$ & $\begin{array}{l}\mathrm{P} \\
\mathrm{R} \\
\mathrm{I} \\
\mathrm{C} \\
\mathrm{E} \\
\mathrm{D}\end{array}$ & $\begin{array}{c}\mathrm{C} \\
\mathrm{R} \\
\mathrm{E} \\
\mathrm{D} \\
\mathrm{I} \\
\mathrm{T} \\
\mathrm{R}\end{array}$ & $\begin{array}{l}\mathrm{A} \\
\mathrm{C} \\
\mathrm{T} \\
\mathrm{I} \\
\mathrm{V} \\
\mathrm{E} \\
\mathrm{R}\end{array}$ \\
\hline 1 & 98.8 & 98.8 & 98.6 & 66.7 & 87.024 & & & & & $X$ & & & & & \\
\hline 1 & 98.5 & 98.4 & 98 & 90.7 & 125.38 & & & & & & & $X$ & & & \\
\hline 2 & 99.7 & 99.7 & 98.6 & 4.5 & 45.779 & $X$ & & & & $X$ & & & & & \\
\hline 2 & 99.6 & 99.6 & 99.5 & 7.4 & 53.599 & $X$ & & & & & & $X$ & & & \\
\hline 3 & 99.7 & 99.7 & 99.6 & 1.9 & 42.807 & $X$ & & & & $X$ & $X$ & & & & \\
\hline 3 & 99.7 & 99.7 & 99.6 & 2.2 & 43.744 & $X$ & & & & $X$ & & $X$ & & & \\
\hline 4 & 99.8 & 99.7 & 99.6 & 0.5 & 40.249 & $X$ & $X$ & & & $X$ & & & & $X$ & \\
\hline 4 & 99.8 & 99.7 & 99.6 & 1.1 & 40.367 & $X$ & & & & $X$ & $X$ & $\mathrm{X}$ & & & \\
\hline 5 & 99.8 & 99.7 & 99.5 & 1.9 & 38.328 & $X$ & $X$ & & & $X$ & & & $X$ & $X$ & \\
\hline 5 & 99.8 & 99.7 & 99.6 & 1.9 & 38.524 & & & $X$ & & $X$ & $X$ & $X$ & & $X$ & \\
\hline 6 & 99.8 & 99.7 & 99.5 & 3.4 & 37.964 & $X$ & $X$ & & & $X$ & & $X$ & $X$ & $X$ & \\
\hline 6 & 99.8 & 99.7 & 99.6 & 3.6 & 38.348 & $X$ & & $X$ & & $X$ & $X$ & $X$ & & $X$ & \\
\hline 7 & 99.8 & 99.7 & 99.4 & 5.1 & 37.521 & $\mathrm{X}$ & $\mathrm{X}$ & & & $\mathrm{X}$ & & $\mathrm{X}$ & $\mathrm{X}$ & $\mathrm{X}$ & $X$ \\
\hline 7 & 99.8 & 99.7 & 99.4 & 5.2 & 38.396 & $\mathrm{X}$ & $X$ & & & $X$ & $X$ & $X$ & $X$ & $\mathrm{X}$ & \\
\hline 8 & 99.8 & 99.7 & 99.4 & 7.1 & 38.358 & $X$ & $X$ & & & $X$ & $\mathrm{X}$ & $X$ & $X$ & $X$ & $X$ \\
\hline 8 & 99.8 & 99.7 & 99.3 & 7.1 & 38.353 & $\mathrm{X}$ & $X$ & $X$ & & $\mathrm{X}$ & $X$ & $\mathrm{X}$ & & $X$ & $X$ \\
\hline 9 & 99.8 & 99.7 & 99.3 & 9.0 & 39.783 & $X$ & $X$ & $X$ & & X & $X$ & $X$ & $X$ & $X$ & $X$ \\
\hline 9 & 99.8 & 99.7 & 99.2 & 9.1 & 39.921 & $X$ & $X$ & & $X$ & X & & $X$ & $X$ & $X$ & $X$ \\
\hline 10 & 99.8 & 99.7 & 99 & 11.0 & 41.552 & $\mathrm{X}$ & $\mathrm{X}$ & $X$ & $X$ & $\mathrm{X}$ & X & $\mathrm{X}$ & X & $X$ & $X$ \\
\hline
\end{tabular}

To develop these three models, a simple multiple regression must be performed. The results showed that the problem of multi-collinearity occurred in the three models. In fact, the coefficient of the variance inflation factor (VIF) is greater than 10 in the three models, which indicate the presence of multicollinearity. Partial least squares regression (PLSR) is the technique used in this kind of problem to reduce the correlation between the predictors. In this case, the three models does not change, so we will use the same equations (1) to (3). 
Table 2. Selected independent variables for the MLR models.

\begin{tabular}{|l|c|c|c|c|c|c|c|c|c|}
\hline & POP & GDP & $\begin{array}{l}\text { PRICEG } \\
\text { (DH) }\end{array}$ & REGISTR & $\begin{array}{l}\text { FLEET } \\
(103 * \text { vehicle })\end{array}$ & $\begin{array}{l}\text { Road } \\
\text { network } \\
\text { (km) }\end{array}$ & EVOL & $\begin{array}{l}\text { PRICED } \\
\text { (DH) }\end{array}$ & $\begin{array}{l}\text { CREDITR } \\
\text { ACTIVER }\end{array}$ \\
\hline MRL1 & & & $\checkmark$ & & $\checkmark$ & & $\checkmark$ \\
\hline MRL2 & $\checkmark$ & & $\checkmark$ & & & $\checkmark$ & $\checkmark$ \\
\hline
\end{tabular}

\section{Forecast and discussion}

After the construction model phase, we can notice from the three previous models that POP, GDP, vehicle fleet and price of diesel are common between the three models, which means that demographic, economic and social growth has a strong impact on energy demand in this sector. To ensure a first change in energy consumption, the government needs to impose some rules to limit the use of vehicle. The three previous models will be used later to forecast Morocco's transport energy demand for the next ten years. Finally, the various possible scenarios for the evolution of the selected variables will be carried out in order to forecast the energy demand of the transport sector. The model testing phase was the first step in the forecasting procedure. Indeed, it was necessary to do the validation step to choose the right model. Hence the need to calculate forecast indicators that provide information on the accuracy between the regression results and actual consumption. These indicators are as follows:

The root mean square error (RMSE) (1), with:

$$
R M S E=\sqrt{\frac{\sum_{i=1}^{n}\left(\widehat{y_{l}}-y_{i}\right)^{2}}{n}}
$$

The mean absolute percentage error (MAPE) (2), with:

$$
M A P E=\frac{\sum_{i=1}^{n}\left|\widehat{y_{l}}-y_{i}\right|}{n}
$$

Where $y_{i}$ is the value of the $i^{\text {th }}$ observation of the validation dataset and ${ }_{i}$ is the predicted value for the $\mathrm{i}^{\text {th }}$ observation.

The results of testing phase are presented in table 3 and 4. According to this tables, we can conclude that the model 1 present the best performance in terms of RMSE and MAPE errors.

The second step is to estimate the future evolution of the explanatory variables. The possible scenarios for the growth of all parameters are shown in Table 5.

Table 3. Model testing phase

\begin{tabular}{|c|c|c|c|}
\hline Year & PLSR1(Ktep) & PLSR2(Ktep) & PLRS3(Ktep) \\
\hline 2012 & 4987,40 & 4995,36 & 5018,27 \\
\hline 2013 & 5317,53 & 5323,38 & 5353,80 \\
\hline 2014 & 5615,56 & 5622,19 & 5674,93 \\
\hline
\end{tabular}

Table 4. Validation phase of the good model

\begin{tabular}{|c|c|c|c|}
\hline & PLSR 1 & PLSR 2 & PLSR 3 \\
\hline RMSE & 408,73 & 414,88 & 452,37 \\
\hline MAPE & $2,54 \%$ & $2,58 \%$ & $8,47 \%$ \\
\hline
\end{tabular}

Table 5. Expected indicators related to Morocco

\begin{tabular}{|c|c|c|c|c|c|}
\hline Year & FLEET & POP & GDP & PRICED & CREDITR \\
\hline 2020 & 3721,73 & 36414,05 & 1096,44 & 8,89 & 37362,61 \\
\hline 2021 & 3820,19 & 36786,26 & 1126,04 & 9,26 & 38735,73 \\
\hline 2022 & 3918,64 & 37158,47 & 1155,64 & 9,63 & 40108,86 \\
\hline 2023 & 4017,10 & 37530,68 & 1185,24 & 10,00 & 41481,98 \\
\hline 2024 & 4115,56 & 37902,89 & 1214,84 & 10,37 & 42855,11 \\
\hline 2025 & 4214,01 & 38275,11 & 1244,44 & 10,74 & 44228,23 \\
\hline 2026 & 4312,47 & 38647,32 & 1274,03 & 11,12 & 45601,36 \\
\hline 2027 & 4410,92 & 39019,53 & 1303,63 & 11,49 & 46974,48 \\
\hline 2028 & 4509,38 & 39391,74 & 1333,23 & 11,86 & 48347,61 \\
\hline 2029 & 4607,84 & 39763,95 & 1362,83 & 12,23 & 49720,73 \\
\hline 2030 & 4706,29 & 40136,16 & 1392,43 & 12,60 & 51093,86 \\
\hline
\end{tabular}

Finally, the demand for transport energy in Morocco is predicted using model PLSR 1(figure 3): 


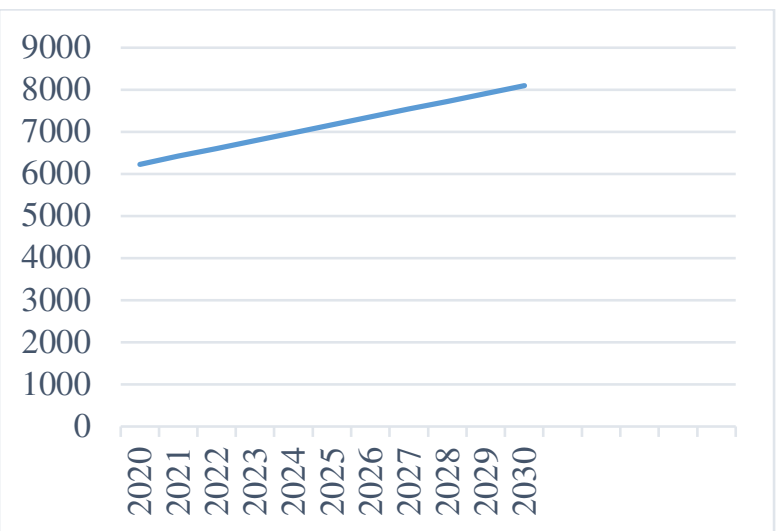

Fig. 3. Expected energy consumption (Kteo) in Morocco

The total transport energy demand for 2030 will reach to a level of about 8095,49 Ktoe (figure 3) with an evolution rate of $91,34 \%$ after the EE strategy (in 2009). This value is calculated from the chosen model which is PLSR 1. We conclude that the evolution rate is too high, which mean that our country must reduce the TEC as much as possible in order to attain the sustainable transport.

\section{Conclusion}

Regression methods can be used as a method for estimating TEC. This study seeks the right model to forecast TEC energy by 2030. the energy demand is analyzed from 1990 until 2014 based on several variables such as, GDP, POP, gasoline price, diesel price, URB, the vehicle fleet, evolution of the number of vehicles, vehicle registration in Morocco.

The forecast results show that transport energy demand in 2020 will be almost twice that of 2009. The best model PLSR chosen in this study is composed of POP, GDP, vehicle fleet, price of diesel and rate of credit. Total transport energy demand in 2030 will reach a level of about 8095,49 Ktoe for PLSR 1.

As a developing country, we need sound planning and/or approaches to using domestic energy sources in the future. The sustainable transport can be achieved only if a lot of control measures are imposed on the use of vehicles. Therefore, Morocco should continue to strive to reduce energy consumption in order to reduce $\mathrm{CO} 2$ emissions and meet its national and international commitments.

In addition, much recent work has focused on improving the accuracy of future energy consumption in several sectors using different techniques. Nevertheless, the results of this modest work constitute the bases of a work to be continued in terms of precision by using other method of prediction. 


\section{Appendix A.}

Table A-1. Trend of the independent variables and transport energy consumption in Morocco.

\begin{tabular}{|c|c|c|c|c|c|c|c|c|c|c|c|}
\hline Year & POP & GDP & $\begin{array}{l}\text { Gas } \\
\text { Price } \\
\text { (DH) }\end{array}$ & $\begin{array}{l}\text { Vehicle } \\
\text { registration }\end{array}$ & $\begin{array}{l}\text { Vehicle fleet } \\
\left(10^{3 *} \text { vehicle }\right)\end{array}$ & $\begin{array}{l}\text { Road } \\
\text { network } \\
(\mathrm{km})\end{array}$ & $\begin{array}{l}\text { Evolution } \\
\text { of the } \\
\text { number of } \\
\text { vehicles }\end{array}$ & $\begin{array}{l}\text { Price } \\
\text { of } \\
\text { diesel } \\
\text { (DH) }\end{array}$ & $\begin{array}{l}\text { Credit } \\
\text { rate in } \\
\text { the } \\
\text { transport } \\
\text { sector }\end{array}$ & $\begin{array}{l}\text { Rate of } \\
\text { active } \\
\text { woman }\end{array}$ & $\begin{array}{l}\text { TEC } \\
\text { (koe) }\end{array}$ \\
\hline 1990 & 24807,462 & 364,34 & 6,7 & 47494 & 937 & 59452 & 971991 & 3,97 & 513 & 23,5 & 1299 \\
\hline 1991 & 25260,404 & 390,64 & 6,7 & 51667 & 988 & 59452 & 1022100 & 3,97 & 978 & 23,73 & 1440 \\
\hline 1992 & 25711,406 & 382,44 & 6,7 & 84585 & 1078 & 59790 & 1105822 & 3,97 & 973 & 23,61 & 1596 \\
\hline 1993 & 26155,203 & 379,28 & 6,7 & 82176 & 1169 & 59790 & 1185755 & 3,97 & 1005 & 23,58 & 1726 \\
\hline 1994 & 26584,478 & 419,81 & 6,7 & 111888 & 1278 & 60449 & 1295999 & 3,97 & 1677 & 23,99 & 1862 \\
\hline 1995 & 26994,25 & 397,11 & 7,03 & 60495 & 1340 & 90449 & 1354990 & 4,2 & 2102 & 23,86 & 1973 \\
\hline 1996 & 27383,473 & 446,25 & 7,24 & 46239 & 1385 & 60449 & 1389576 & 4,55 & 2318 & 24,38 & 2106 \\
\hline 1997 & 27754,571 & 439,28 & 7,47 & 56441 & 1439 & 57520 & 1446017 & 4,92 & 1832 & 24,45 & 2247 \\
\hline 1998 & 28110,443 & 471,08 & 7,13 & 66602 & 1504 & 57520 & 1510843 & 4,46 & 2083 & 24,87 & 2389 \\
\hline 1999 & 28455,509 & 476,17 & 7,16 & 73223 & 1581 & 57222 & 1582526 & 4,54 & 3254 & 25,07 & 2548 \\
\hline 2000 & 28793,679 & 485,28 & 8,14 & 65789 & 1655 & 57227 & 1647269 & 5,43 & 4202 & 25,27 & 2680 \\
\hline 2001 & 29126,33 & 520,80 & 8,65 & 59014 & 1719 & 57227 & 1704633 & 5,76 & 4909 & 25,63 & 2832 \\
\hline 2002 & 29454,768 & 537,06 & 8,65 & 56111 & 1786 & 57225 & 1760774 & 5,76 & 6649 & 25,28 & 2967 \\
\hline 2003 & 29782,884 & 569,08 & 8,65 & 52310 & 1853 & 57733 & 1813084 & 5,76 & 7382 & 26,39 & 3090 \\
\hline 2004 & 30115,214 & 596,37 & 8,78 & 59418 & 1928 & 56986 & 1872502 & 5,84 & 8088 & 26,88 & 3201 \\
\hline 2005 & 30455,561 & 616,00 & 9,08 & 59878 & 2013 & 57226 & 1932380 & 6,46 & 14993 & 26,97 & 3332 \\
\hline 2006 & 30804,683 & 662,67 & 10,54 & 112021 & 2147 & 57227 & 2146621 & 6,74 & 19247 & 26,85 & 3433 \\
\hline 2007 & 31163,673 & 686,07 & 10,26 & 138719 & 2284 & 57227 & 2284060 & 7,13 & 21987 & 26,66 & 3650 \\
\hline 2008 & 31536,811 & 726,70 & 10,75 & 153276 & 2436 & 57852 & 2436204 & 7,22 & 23557 & 26,52 & 3999 \\
\hline 2009 & 31929,087 & 757,55 & 10,32 & 189665 & 2625 & 57299 & 2624858 & 7,56 & 23933 & 26,47 & 4231 \\
\hline 2010 & 32343,389 & 786,45 & 10,18 & 167039 & 2791 & 57298 & 2791004 & 7,15 & 24689 & 26,43 & 4452 \\
\hline 2011 & 32781,85 & 827,71 & 10,18 & 164291 & 2954 & 58696 & 2954073 & 7,15 & 28290 & 26,37 & 4712 \\
\hline 2012 & 33241,898 & 852,62 & 11,26 & 171628 & 3124 & 58893 & 3124402 & 7,69 & 28901 & 25,89 & 4782 \\
\hline 2013 & 33715,693 & 891,29 & 12,27 & 163185 & 3286 & 58714 & 3286421 & 8,39 & 28460 & 25,84 & 4970 \\
\hline 2014 & 34192,347 & 915,08 & 12,78 & 152740 & 3438 & 57334 & 3437948 & 9,26 & 28588 & 25,39 & 5034 \\
\hline
\end{tabular}

\section{References}

[1] «Les prévisions de l'AIE pour 2021: «un sombre avertissement »|Connaissances des énergies », avr. - 12:00 2021. https://www.connaissancedesenergies.org/lesprevisions-de-laie-pour-2021-un-sombre-avertissement210421 (consulté le sept. 12, 2021).

[2] 《Tracking Transport 2020 - Analysis », IEA. https://www.iea.org/reports/tracking-transport-2020 (consulté le nov. 01, 2021).

[3] O. Mazurova et E. Galperova, « Energy Consumption in the Transport Sector: Trends and Forecast Estimates », in 2018 International Multi-Conference on Industrial Engineering and Modern Technologies (FarEastCon),

Vladivostok, oct. 2018, p. 1-7. doi:

10.1109/FarEastCon.2018.8602478.

[4] «AMEE | Transport ».

https://www.amee.ma/fr/expertise/transport (consulté le sept. 12, 2021).

[5] «Transport - Topics », IEA.

https://www.iea.org/topics/transport (consulté le sept. 13, 2021).

[6] Z. W. Geem, « Transport energy demand modeling of South Korea using artificial neural network », Energy Policy, vol. 39 , no 8 , p. $4644-4650$, août 2011 , doi:

10.1016/j.enpol.2011.05.008.

[7] M. Zhang, H. Mu, G. Li, et Y. Ning, «Forecasting the transport energy demand based on PLSR method in China ", Energy, vol. 34, n 9, p. 1396-1400, sept. 2009, doi: 10.1016/j.energy.2009.06.032.

[8] M. Maduekwe, U. Akpan, et S. Isihak, « Road transport energy consumption and vehicular emissions in Lagos, Nigeria: An application of the LEAP model », Transportation Research Interdisciplinary Perspectives, vol. 6, p. 100172, juill. 2020, doi: 10.1016/j.trip.2020.100172. [9] V. Plakandaras, T. Papadimitriou, et P. Gogas, « Forecasting transportation demand for the U.S. market », Transportation Research Part A: Policy and Practice, vol. 126, p. 195-214, août 2019, doi: 10.1016/j.tra.2019.06.008. [10] A. Kialashaki et J. R. Reisel, « Modeling of the energy demand of the residential sector in the United States using regression models and artificial neural networks », Applied Energy, vol. 108, p. 271-280, août 2013, doi:

10.1016/j.apenergy.2013.03.034.

[11] S. Guefano, J. G. Tamba, T. E. W. Azong, et L. Monkam, « Forecast of electricity consumption in the Cameroonian residential sector by Grey and vector autoregressive models », Energy, vol. 214, p. 118791, janv. 2021, doi: 10.1016/j.energy.2020.118791. 
[12] M. Gholami, D. Torreggiani, P. Tassinari, et A. Barbaresi, « Narrowing uncertainties in forecasting urban building energy demand through an optimal archetyping method », Renewable and Sustainable Energy Reviews, vol. 148, p. 111312, sept. 2021, doi: 10.1016/j.rser.2021.111312. [13] O. F. Beyca, B. C. Ervural, E. Tatoglu, P. G. Ozuyar, et S. Zaim, « Using machine learning tools for forecasting natural gas consumption in the province of Istanbul », Energy Economics, vol. 80, p. 937-949, mai 2019, doi:

10.1016/j.eneco.2019.03.006.

[14] N. Somu, G. Raman M R, et K. Ramamritham, « A deep learning framework for building energy consumption forecast », Renewable and Sustainable Energy Reviews, vol. 137, p. 110591, mars 2021, doi: 10.1016/j.rser.2020.110591. [15] Nhat Hai NGUYEN, « Développement de méthodes intelligentes pour la gestion énergétique des bâtiments, utilisant des capteurs sans fil », de Grenoble, l'École Doctorale «Electronique, Electrotechnique, Automatique, Télécommunication et Signal », 2011.

[16] M. Kharbach et T. Chfadi, « CO2 emissions in Moroccan road transport sector: Divisia, Cointegration, and EKC analyses », Sustainable Cities and Society, vol. 35, p. 396-401, nov. 2017, doi: 10.1016/j.scs.2017.08.016.

[17] Y. Maaroufi, « Open Data», Site institutionnel du Haut-Commissariat au Plan du Royaume du Maroc. https://www.hcp.ma/Open-Data_a2401.html (consulté le nov. 02, 2021)

[18] «Data overview », IEA. https://www.iea.org/data-andstatistics (consulté le sept. 13, 2021).

[19] S. A. Nabavi, A. Aslani, M. A. Zaidan, M. Zandi, S. Mohammadi, et N. Hossein Motlagh, « Machine Learning Modeling for Energy Consumption of Residential and Commercial Sectors », Energies, vol. 13, n ${ }^{\circ}$ 19, p. 5171, oct. 2020, doi: 10.3390/en13195171. 